\title{
O TEU MESTRE- PLATAFORMA DE ENSINO À DISTÂNCIA
}

\author{
Daniel Azevedo ${ }^{1}$ e Paula Morais ${ }^{2}$ \\ ${ }^{1}$ Polytechnic Institute of Viseu, Portugal \\ ${ }^{2}$ Portucalense University, Portugal
}

\begin{abstract}
RESUMO
Os processos de ensino e de aprendizagem estão em fase de mudança. Nas últimas três décadas, tem-se assistido à criação e crescimento de uma geração digital em que o uso e constante evolução das tecnologias de informação e dos recursos educativos digitais a elas associados têm vindo a transformar todo o processo educacional. De facto, os recursos educativos digitais (RED) têm tido um impacto positivo nas aprendizagens dos alunos em diversas disciplinas nomeadamente na matemática, fortalecendo a criatividade, o pensamento crítico e permitindo o ensino na sala de aula e fora dela. Neste contexto, o objetivo principal deste trabalho é propor um modelo de um RED que suporte e potencie a aprendizagem da Matemática, não só aos alunos do ensino regular, mas também aos que se encontram hospitalizados e/ou impedidos de estarem presentes na sala de aula. $\mathrm{O}$ modelo proposto foi validado através de um estudo de caso desenvolvido durante o $2^{\circ}$ e $3^{\circ}$ períodos do ano letivo 2014/2015, envolvendo alunos de ensino especial, em contexto hospitalar, alunos de uma turma de Matemática A do $12^{\circ}$ ano de uma escola do Porto e professores de Matemática do ensino secundário.
\end{abstract}

\section{PALAVRAS-CHAVE}

Recursos Educativos Digitais, Plataforma Educativa, Inovação Educativa, Apoio Escolar a Alunos Hospitalizados, Ensino da Matemática

\section{INTRODUÇÃO}

Vivemos na era das tecnologias. Estas invadem o nosso quotidiano, desde as simples brincadeiras das crianças até aos procedimentos mais complexos da medicina. O mesmo se aplica à Educação. De facto, segundo Vieira (2005), as Tecnologias de Informação e Comunicação (TIC) estão cada vez mais presentes em todos os domínios da atividade social e têm contribuído para mudar a escola e o seu papel na sociedade. Assim, faz sentido a crescente aposta tecnológica dos sucessivos governos nas escolas.

Já em 2002, Ponte afirmava que a introdução das TIC no ensino não é uma mera substituição dos meios tradicionais ou do professor, mas sim um agente ativo de mudança na forma como se aprende, como se ensina e na interação entre professor e aluno na sala de aula.

Esta nova forma de estar na educação é corroborada pela UNESCO (2009), que defende a educação para todos através das TIC. Esta inclusão das tecnologias na educação permite simultaneamente personalizar a aprendizagem, alargá-la a outros públicos-alvo e transpor a barreira física da sala de aula, levando a escola ao aluno.

Embora existam vários recursos disponíveis na web, há um desconhecimento generalizado, por parte da comunidade educativa, sobre a sua existência (Ramos, 2010).

No caso de alunos com necessidades educativas especiais (NEE) que se encontram impossibilitados de assistir às aulas por motivos de doença (ou outro), os recursos educativos digitais poderão ser um auxílio importante no acompanhamento do seu percurso escolar (Mourato, 2011).

É, pois, neste contexto que se insere o presente trabalho. Pretende-se, através do uso de recursos educativos digitais (RED), contribuir para o apoio aos alunos do ensino tradicional e também dar apoio escolar a alunos hospitalizados e/ou impedidos de estar presentes na sala de aula. 
As dificuldades encontradas pelos alunos, quanto à aprendizagem, em particular da Matemática, segundo Silva (n.d.) são reflexos da capacitação deficitária dos professores e de inserir recursos pedagógicos desadequados e, muitas vezes, descontextualizados.

No caso particular da Matemática, continua-se a assistir a um problema recorrente de médias dos exames nacionais relativamente baixas em 2013 (8,2 valores) e em 2014 (7,7 valores).

Se considerarmos os alunos hospitalizados e/ou impedidos de estarem presentes na sala de aula, estas dificuldades são ainda mais evidenciadas. Correia (1997) considera especiais estes alunos com necessidades educativas, uma vez que exibem determinadas condições específicas e podem necessitar de apoios e serviços de educação especial durante todo ou parte do seu percurso escolar, de forma a facilitar o seu desenvolvimento académico, pessoal e socio-emocional.

Grande parte destes alunos está hospitalizada por longos períodos e depara-se com um ambiente desconhecido, com a agravante de estarem afastados do meio familiar, social e escolar.

$\mathrm{O}$ apoio escolar a estes alunos confronta-se com inúmeras dificuldades, das quais se salienta a burocratização, a UNESCO (2009), refere que as práticas escolares são burocráticas, criando barreiras à aprendizagem.

Neste contexto, os RED podem ser encarados como um meio para combater as dificuldades do ensino dos alunos do ensino tradicional e dos alunos que estão hospitalizados.

Estes RED, no caso dos alunos hospitalizados e/ou impedidos de assistir às aulas, permitem combater o isolamento dos alunos e ligá-los à comunidade escolar, proporcionando novas formas de aprender.

Para este estudo foi escolhida a disciplina de Matemática; esta escolha prendeu-se com a experiência dos autores no apoio aos alunos hospitalizados e também da constatação do facto de que a generalidade dos alunos não têm uma boa relação com esta disciplina, embora os resultados internacionais tenham vindo a contrariar esse sentimento.

Tendo em conta estas dificuldades, surge este projeto, com o objetivo principal de propor um modelo de um RED para potenciar a aprendizagem da Matemática de alunos do ensino tradicional e de alunos hospitalizados e/ou impedidos de estarem presentes na sala de aula.

\section{METODOLOGIA}

Neste estudo serão usadas abordagens qualitativas e quantitativas e um estudo de caso que foi desenvolvido com uma abordagem mista, com o objetivo de avaliar a plataforma educativa e recolher informação que permita corrigir alguns aspetos e melhorá-la no futuro.

Este estudo de caso foi dividido em 4 fases que podemos resumir em: 1. O protótipo da plataforma "O teu Mestre"; 2. Apresentação e formação da Plataforma; 3. Acompanhamento da utilização da plataforma pelos alunos; 4. Análise dos resultados dos inquéritos preenchidos pelos intervenientes. Devido à complexidade e abrangência do estudo, este artigo reflete os três primeiros pontos, sendo o quarto ponto objeto de análise em outro artigo científico.

Os participantes neste estudo foram: Uma turma do $12^{\circ}$ ano constituída por 17 alunos do ensino público, com frequência da disciplina de Matemática A, do Agrupamento de Escolas Fontes Pereira de Melo, no Porto.

Quatro alunos sinalizados pela Associação Acreditar (Associação de Pais e Amigos de Crianças com Cancro);

Estes alunos estão grande parte do tempo hospitalizados e/ou impedidos de estarem presentes na sala de aula;

De modo a validar esta colaboração foi estabelecido um protocolo entre o autor e a Acreditar. Neste sentido, foram considerados neste estudo 4 alunos que padecem de doença oncológica e que alternaram entre regime hospital e regime ambulatório.

Foram considerados cinco professores de matemática com uma experiência superior a cinco anos que utilizaram a plataforma educativa. Quatro destes professores do distrito de Viseu utilizaram esta plataforma.

No caso da docente da turma da Escola Fontes Pereira de Melo utilizou esta plataforma como recurso educativo em sala de aula.

A recolha de dados foi feita através de diferentes métodos e técnicas que se complementam entre si, nomeadamente: o diário de bordo e um inquérito por questionário. $\mathrm{O}$ diário de bordo foi um dos instrumentos 
do estudo de caso, uma vez que houve necessidade de registar todo o acompanhamento feito aos alunos através da plataforma educativa. Este registo iniciou-se no começo do segundo período do ano letivo 2014/2015, uma vez que os alunos sinalizados pela Acreditar e da Escola Fontes Pereira de Melo estavam aptos a utilizar a plataforma. De uma forma geral este registo permitiu observar as dificuldades dos alunos, tanto ao nível pedagógico como tecnológico.

Neste estudo optámos por 3 questionários, um direcionado aos alunos da turma do $12^{\circ}$ ano do Agrupamento de Escolas Fontes Pereira de Melo, um segundo aos alunos sinalizados pela Acreditar, e o último aos professores que tiveram contacto com a plataforma.

O objetivo destes questionários consistiu na avaliação do protótipo da plataforma educativa a que tiveram acesso. O desenho dos 3 questionários teve como base os critérios da tabela de Learning Object Review Instrument (LORI) que analisa os itens: qualidade de conteúdo, objetivo da aprendizagem, adaptação e feedback, motivação, apresentação e design, usabilidade, acessibilidade, reutilização, cumprimentos de normas.

Tivemos ainda em conta na elaboração dos questionários, questões de ética como o consentimento informado, o anonimato e a confidencialidade dos dados.

\section{RECURSOS EDUCATIVOS DIGITAIS}

A OCDE considera que qualquer recurso digital que seja utilizado para fins de aprendizagem é um RED (OCDE, 2007). Esta, apresenta-se como uma das definições mais simplista que estabelece que todos os materiais educativos baseados nas TIC que os professores e alunos usam para ensinar e aprender podem ser considerados RED.

No âmbito do trabalho da equipa de recursos e tecnologias educativas (ERTE), é apresentada uma primeira definição de RED, (Ramos, Duarte, Carvalho, Ferreira \& Maio, 2007), que considera como essencial que um RED, tenha quatro atributos:

- RED deve ter uma clara finalidade educativa, ou seja, quando é pensado, desenhado e elaborado com uma finalidade educativa;

- RED deve poder responder a necessidades do sistema educativo português (p.e., currículos da educação formal, informal e não-formal, formação profissional);

- RED deve apresentar uma identidade autónoma relativamente a outros objetos e serviços de natureza digital;

- RED deve satisfazer critérios pré-definidos de qualidade nas suas dimensões essenciais.

Em 2011, no âmbito da definição anterior os autores, Ramos, Teodoro e Ferreira, reformulam essa mesma definição e consideram:

"software e recursos educativos digitais consistem em entidades digitais produzidas especificamente para fins de suporte ao ensino e à aprendizagem."(p.13).

Assim, este conceito é abrangente e considera como recursos educativos digitais, jogos educativos, programas informáticos de modelação ou simulação, vídeos, tutoriais que exemplificam ou propõem a prática de exercícios, ambientes de autor ou recursos viabilizados pela web, como a criação de blogues, apresentações dinâmicas, entre outros. Desde que estejam armazenados em suporte digital e que "levem em linha de conta, na sua conceção, considerações pedagógicas" (Tchounikine, citado em Ramos, Teodoro \& Ferreira 2011. p.13).

No âmbito deste trabalho iremos adotar a definição de RED de Ramos, Teodoro e Ferreira (2011) que considera:

"Software e recursos educativos digitais consistem em entidades digitais produzidas especificamente para fins de suporte ao ensino e à aprendizagem"

Esta definição, como abordamos anteriormente, poderá corresponder a inúmeros recursos, Pinto (2007), embora referindo que não existe uma classificação clara dos recursos educativos digitais, considera as seguintes categorias: i) software educativo; ii) plataformas educativas; iii) portais de conteúdo; iv) tutoriais de aprendizagem; v) portefólios digitais; vi) portais de recursos.

Além disso, considera que um RED tem várias categorias com as seguintes caraterísticas: são facilmente manipuláveis, rapidamente transformáveis, transportados instantaneamente e infinitamente replicados, em contraponto aos recursos impressos. 
Os RED são caraterizados pela utilização do hipertexto, de conteúdos e de atividades, incluindo as que contemplam a possibilidade da interação com os alunos (Pinto, 2007). Uma plataforma educativa, segundo Carvalho (2007) é considerada como um conjunto de ferramentas que facilitam a disponibilização de recursos em vários formatos como texto, vídeo e áudio, apontadores para sites, avisos aos alunos, interação professor-alunos através de ferramentas de comunicação, ferramentas de apoio à aprendizagem colaborativa e registo das atividades realizadas pelos alunos.

\subsection{RED no Apoio a Alunos Hospitalizados}

Segundo Correia (1997), o conceito de necessidades educativas especiais (NEE) surge de uma evolução nos conceitos que até então se usavam, quer de cariz social, quer de educacional. "O termo NEE vem, assim, responder ao princípio da progressiva democratização das sociedades, refletindo o postulado na filosofia da integração e proporcionando uma igualdade de direitos, nomeadamente o que diz respeito à não descriminação por razões de raça, religião, opinião, características intelectuais e físicas, a toda a criança e adolescente em idade escolar" (Correia, 1997, p. 373). Segundo o mesmo autor, o conceito aplica-se a crianças e adolescentes com problemas sensoriais, físicos, intelectuais e emocionais e, também, com dificuldades de aprendizagem derivadas de fatores orgânicos ou ambientais. Neste sentido, os alunos hospitalizados são caraterizados como alunos com NEE.

Estes alunos em internamento hospitalar, por si só, encontram-se numa situação complicada, porque, à partida, vêm-se privados do seu meio natural de crescimento. $O$ apoio e a interação são, por isso, fundamentais para o doente.

Scremin \& Schumacher (2019) consideram que deverá ser estabelecida uma cooperação entre as equipas médicas, psicólogos e assistentes sociais e os professores, de modo a suprir as dificuldades, e a criar condições de melhoria na aprendizagem e saúde do aluno.

As atividades desenvolvidas nas instituições hospitalares têm como função, não só o apoio escolar, mas também a vertente lúdica, proporcionando aos alunos momentos de bem-estar e segurança, ocupando os seus tempos livres com atividades que lhes são benéficas, reforçando assim as suas competências e capacidades.

Este apoio educativo foi consagrado em 1988, altura da criação da "Carta da Criança Hospitalizada". Este documento foi redigido por várias associações internacionais, cabendo ao Instituto de Apoio à Criança representar Portugal.

As tecnologias têm tido um papel fundamental de apoio aos alunos hospitalizados e têm por objetivo compensar uma limitação funcional e facilitar um modo de vida independente, sendo por isso elementos facilitadores do desempenho de atividades e da participação dos alunos (Decreto-lei nº 3 /2008). Hylén (2007) considera que uma das vantagens dos RED é a possibilidade de permitir a individualização dos processos de ensino e aprendizagem. Esta vantagem, no caso particular dos alunos impossibilitados de aceder ao ensino tradicional é uma mais valia e, muitas vezes, a única forma de contacto.

Com a crescente evolução das tecnologias torna-se fundamental a criação de recursos educativos digitais com intuito de responder às necessidades dos alunos que se encontram num ambiente hospitalar. Estes recursos podem permitir diferentes tipos de navegação, fazendo depender a sua utilização de prévia preparação do professor, de forma contextualizada e mediando uma aprendizagem autónoma, de acordo com o ritmo e estilo de aprendizagem do aluno (Falkembach, 2005).

Estes recursos, para Sparrowhawk \& Heald (2007), no caso dos alunos hospitalizados e/ou impedidos de assistir às aulas, podem auxiliar o processo de ensino e de aprendizagem, aumentando a motivação e proporcionando um leque de oportunidades diferenciado, principalmente para os alunos cujos padrões de aprendizagem não seguem os quadros típicos de desenvolvimento. Verifica-se que quando comparada com a educação tradicional, a educação complementada com a tecnologia é mais eficaz e eficiente, principalmente devido à acrescida motivação incrementada pela interação disponibilizada (Ribeiro, 2002).

A escolha de um RED adequado para um aluno com NEE não é fácil, mas a verificação destas caraterísticas é essencial para a adequação do ensino às suas limitações.

A BECTA (2008), British Educational Communications and Technology, um organismo não-governamental público britânico, ligado à investigação sobre a utilização das tecnologias nos diferentes níveis de ensino e educação do Reino Unido, onde se inclui a utilização em alunos com necessidades educativas especiais, considera que os RED deverão responder aos seguintes requisitos: 
- Favorecer a inclusão e o acesso ao conhecimento;

- Favorecer o envolvimento dos estudantes na aprendizagem, motivando-os, estimulando-os e desafiando-os na construção de novos conhecimentos;

- Favorecer a inovação e novas abordagens pedagógicas;

- Facilitar o uso pelos estudantes e professores;

- Favorecer a convergência curricular e de desempenhos;

- Orientar e apoiar o progresso nas aprendizagens;

- Favorecer a avaliação;

- Favorecer e potenciar uma aprendizagem efetiva e eficaz.

Segundo este estudo deverá ainda haver uma preocupação com um design amigável de interação com o aluno de modo a responder facilmente às suas dificuldades.

\subsection{Avaliação de RED}

O aumento da quantidade de materiais pedagógicos em suporte informático leva a que seja necessário refletir acerca da qualidade técnica e pedagógica desses materiais, assim como acerca das suas condições de uso, segundo Lévy (2000) a diversidade e multiplicidade da informação disponível não é garantia de qualquer qualidade.

Hoje em dia os professores têm à sua disposição inúmeros recursos educativos digitais para auxiliar o ensino/aprendizagem dos alunos. Mas a proliferação desses conteúdos não tem por base uma estratégia global; segundo Ramos (2010), a criação e a utilização de recursos deverá ser estabelecida por políticas educativas que permitam levar em consideração não apenas a sua criação, a sua distribuição e a sua avaliação, mas também as condições de uso e de integração no trabalho educativo dos professores e dos estudantes, assim como na formação dos professores e no provimento de equipamentos e de tecnologias apropriadas nas escolas. No ano de 2004, em Portugal, o Ministério da Educação criou uma equipa de especialistas e professores com o objetivo de desenvolver um sistema de recolha, disseminação, avaliação e certificação de produtos educativos em suporte digital (Costa, Peralta \& Viseu, 2007) que se designou por projeto SACAUSEF (Sistema de Avaliação, Certificação e Apoio à Utilização de Software para a Educação e a Formação).

\section{PROJETO DA PLATAFORMA - O TEU MESTRE}

Tendo em conta o apoio desenvolvido desde 2009 aos alunos indicados pelo Instituto Português de Oncologia do Porto (IPO), desde cedo houve uma necessidade de criar uma solução de modo a centralizar os conteúdos e facilitar a aprendizagem dos alunos que se encontravam hospitalizados ou que estavam em casa, mas que não frequentavam a escola. Esta preocupação foi referida pela equipa pedagógica do IPO do Porto desde a primeira hora, o que permitiu que o projeto tivesse uma evolução, culminado com a apresentação deste estudo.

Assim, a conceção de um modelo de um RED, em particular, uma plataforma educativa que designámos por "O teu Mestre", pretende apoiar a aprendizagem dos alunos que estejam hospitalizados e ou impedidos de aceder à sala de aula. Além destes alunos foi alargada a abrangência da plataforma a alunos do ensino oficial para uma melhor avaliação e melhoria da mesma.

Numa primeira fase de análise de plataformas já existentes, considerámos que estas apresentam inúmeras soluções e funcionalidades, mas sem responder às necessidades dos alunos. Ao criar uma nova plataforma de raiz podemos ajustar e melhorar a plataforma para ir ao encontro de um melhor apoio escolar aos alunos, e em particular aos alunos hospitalizados.

Na fase seguinte, passámos à fase da conceptualização do modelo da plataforma "O teu Mestre". Este modelo surgiu tendo em conta a vivência prática, num processo de investigação desde 2009, de testes e de análise das necessidades dos alunos.

Surge assim a conceção de modelo de uma plataforma educativa que teve na origem duas ideias chave:

- Simplicidade;

- O que o aluno precisa?. 
O modelo da plataforma educativa "O teu Mestre" compreende "Atividades" e o serviço "Tens uma Dúvida?". Para efetuar o estudo de caso foi implementado um protótipo do modelo que seguidamente se descreve.

O protótipo inclui um backoffice que gere toda a parte de inserção e organização de conteúdos. A organização desta área foi feita com o objetivo de ser intuitiva e de fácil navegação privilegiando-se os menus em imagem em detrimento de palavras (figura 1).

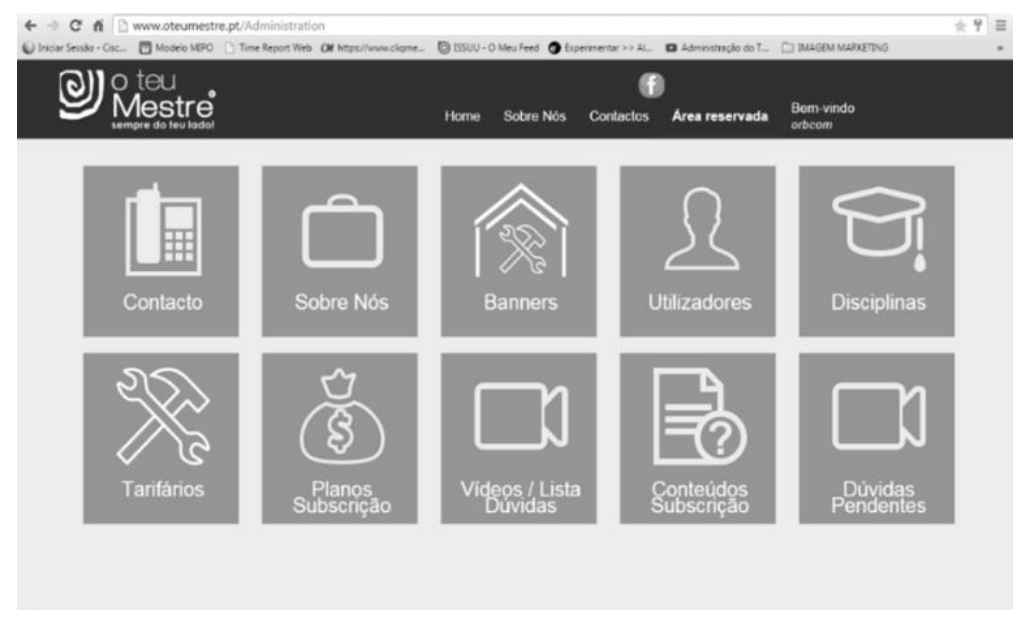

Figura 1. Backoffice da plataforma "O Teu Mestre"

Estes menus permitem aos administradores e professores facilmente inserir exercícios e vídeos numa organização em árvore.

$\mathrm{Na}$ vertente do aluno como utilizador da plataforma e, após o registo e autenticação, este acede à "A minha área". Este local permite visualizar e alterar os seus dados pessoais e aceder à informação das "Atividades" e ao serviço "Tens uma dúvida?",

Após ter efetuado a autenticação, o aluno tem acesso às atividades e serviços da Disciplina de Matemática $12^{\circ}$ Ano.

A disciplina de Matemática $12^{\circ}$ Ano permite ao aluno ter um resumo do essencial que é abordado no ano letivo da disciplina de matemática de $12^{\circ}$ ano, tendo a possibilidade de verificar a sua aprendizagem através exercícios interativos. Além disso, permite ao aluno aprender passo a passo, seguindo o trajeto delineado pela equipa pedagógica que considerou como abordagem inicial os conceitos teóricos, seguidos de exercícios em formato quizzes que permitem ao aluno verificar os seus conhecimentos.

Refira-se que na criação destes conteúdos foi necessária uma análise de manuais escolares do $12^{\circ}$ ano da disciplina de matemática e de outros recursos que apoiam essa disciplina de modo a resumir esses conteúdos. Todos os conteúdos da disciplina de Matemática A, apresentados na plataforma, foram criados pelos autores.

A organização da disciplina de Matemática $12^{\circ}$ Ano é dividida em: Probabilidades, Funções, Trigonometria e Complexos, Dicas, Mobile, Testes Intermédios e Exames.

Nos itens Probabilidades, Funções, Trigonometria e Complexos são apresentados os conteúdos de apoio aos conceitos teóricos. Estes conceitos teóricos são abordados através de resumos em formato $P D F$.

Os quizzes inseridos neste item permitem ao aluno verificar a aprendizagem dos conceitos teóricos. Foi ainda incluída a funcionalidade de apresentar a resposta certa caso o aluno falhe a questão.

Os resumos que apresentamos nestes temas foram criados devido aos alunos sinalizados pela Acreditar terem acesso a um enorme número de fichas, testes e outros recursos enviados pelas escolas e professores o que prejudicava a sua aprendizagem. Neste sentido, criámos um resumo e um formulário em formato papel que fizesse uma síntese desses conteúdos, que disponibilizámos a todos os alunos da Associação Acreditar e da Escola Fontes Pereira de Melo.

Em cada tema, probabilidades, funções, trigonometria e complexos, são também apresentados os "erros comuns", como podemos visualizar na figura 2, que consistem numa análise e recolha dos autores desde 2009. 


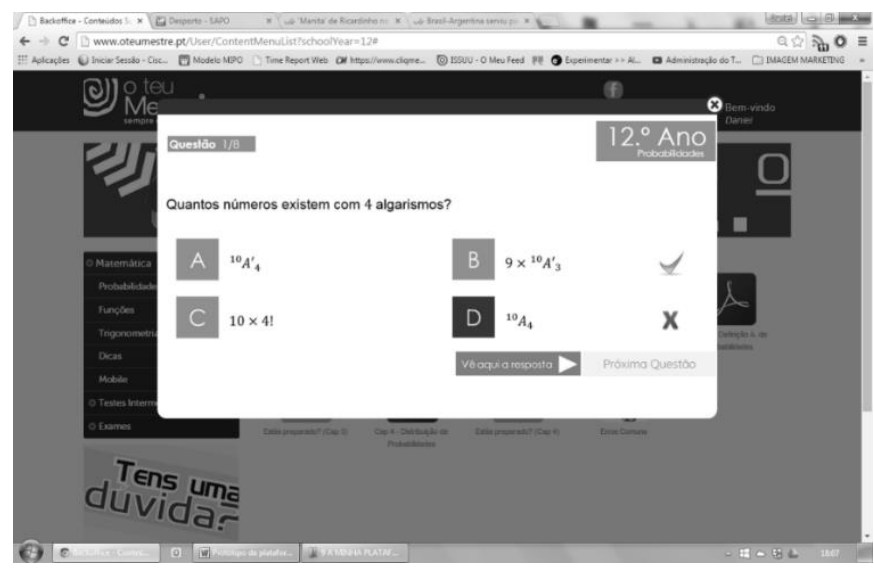

Figura 2. Ambiente de trabalho "Erros Comuns"

Nestes quizzes, foi-se acrescentado a possibilidade de o aluno visualizar a resolução da questão em formato de vídeo. Este vídeo consiste na resolução por parte de um professor.

No item dicas é pretendido que o aluno seja alertado para algumas informações que não são disponibilizadas pelos livros, como cuidados a ter na resolução de exercícios.

Neste item foram disponibilizados vídeos sobre alguns aspetos, como por exemplo: Explicação do formulário do exame nacional e como aplicá-lo; Cuidados a responder a escolhas múltiplas; Alertas sobre "pistas" nos exames como por exemplo textos a negrito; Dicas gerais para resolver exercícios.

No item mobile é pretendido que o aluno possa descarregar para o smartphone ou tablet conteúdos de resumo teórico, aos quais poderá aceder quando estiver a resolver um exercício e sempre que precisar. Estes conteúdos foram divididos em formulário e essencial teórico e podem ser utilizados sem ligação à internet.

O serviço "Tens uma dúvida?" apresenta-se como um serviço que permite dar uma resposta às dúvidas dos alunos, em particular dos alunos hospitalizados. É possível esclarecer dúvidas de um exercício de um livro, exame, ficha fornecida pelo professor, ou qualquer dúvida que o aluno possa ter.

Neste sentido foi necessário estruturar um serviço que fosse de fácil de utilização pelo aluno. A estrutura que foi idealizada está esquematizada na figura 3.

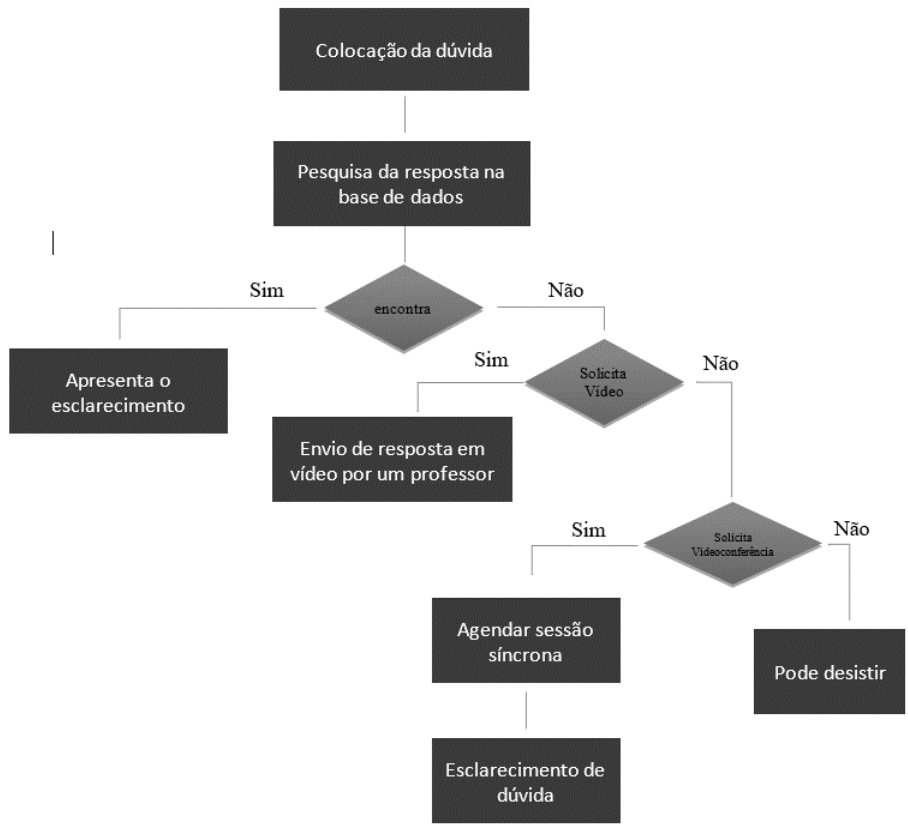

Figura 3. "Serviço Tens uma dúvida?" 
Este serviço passa por criar uma base de dados de exercícios resolvidos em vídeo por um professor e que estejam disponíveis para pesquisa por parte dos alunos.

O aluno ao fazer a pesquisa poderá visualizar a dúvida ou caso não a encontre, poderá solicitá-la através do preenchimento de um formulário (figura 4).

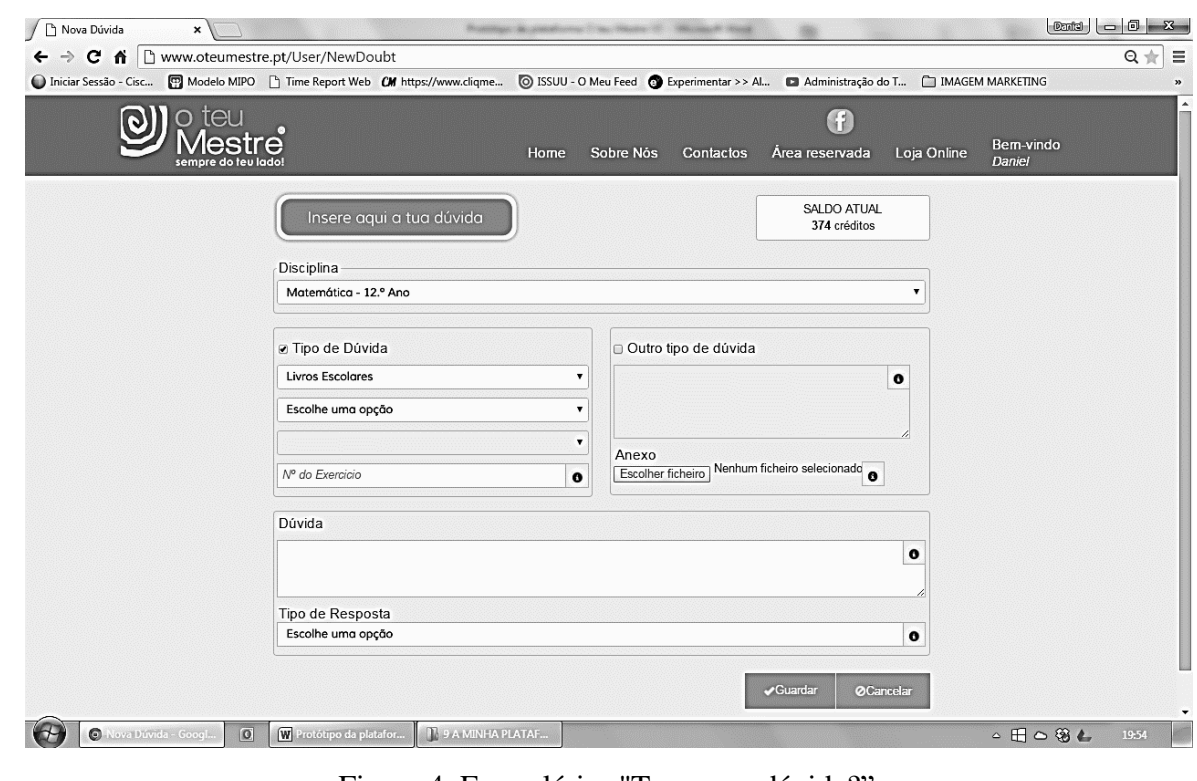

Figura 4. Formulário -"Tens uma dúvida?"

Neste serviço também é disponibilizada uma página "as minhas dúvidas" que permite ao aluno visualizar, sempre que queira, a resolução das dúvidas que solicitou.

A mais-valia deste serviço prende-se com a possibilidade de um aumento de dúvidas disponíveis para os alunos, uma vez que todas as dúvidas esclarecidas em vídeo poderão ser catalogadas e disponibilizadas para pesquisa por outros alunos.

\section{CONCLUSÃO}

Vivemos numa fase de mudança de mentalidades e consequente mudança nos processos de aprendizagem. Desta forma, é necessário criar novas metodologias e práticas alternativas para aprender, ensinar e, mais importante ainda, para aprender a aprender.

Pela análise da fundamentação teórica efetuada e pelos resultados alcançados, podemos afirmar que atingimos o objetivo orientador desta investigação, ou seja, a criação de um modelo de um RED, a plataforma educativa "O teu Mestre", que potencia a aprendizagem da Matemática de alunos do ensino tradicional e de alunos hospitalizados e/ou impedidos de estarem presentes na sala de aula. De facto, concluímos que este modelo de plataforma educativa contribui para o sucesso na disciplina de matemática, ao funcionar como um importante complemento e agente motivador do processo de ensino-aprendizagem, dentro e fora da sala de aula. No caso particular dos alunos hospitalizados, é notório que o modelo de RED aqui apresentado permite apoiar estes alunos sem a necessidade de recursos humanos com dedicação exclusiva a estes alunos. Permite ainda organizar os conteúdos em contraponto com a falta de autonomia da escola que contribui involuntariamente para um ensino desorganizado e não adequado às necessidades $\mathrm{e}$ realidade atual do aluno.

\section{AGRADECIMENTO}

Esta investigação foi apoiada pela Associação Acreditar (Associação de Pais e Amigos de Crianças com Cancro) e pelo Agrupamento de Escolas Fontes Pereira de Melo do Porto. 


\section{REFERÊNCIAS}

BECTA. (2008). Analysis of emerging trends affecting the use of technology in education. www.becta.org.uk

Carvalho, A. (2007). Rentabilizar a Internet no Ensino Básico e Secundário: dos Recursos e Ferramentas Online aos LMS. Sísifo. Revista de Ciências da Educação,3, 25-39.

Correia, L. M. (1997). Alunos com Necessidades Educativas Especiais na Classe Regular. Porto Editora.

Costa, F A; Peralta, H., \& Viseu, S. (orgs). (2007). As TIC na Educação em Portugal. Concepções e Práticas (p. 368). Porto: Porto Editora.

Falkembach. M. (2005). Concepção e Desenvolvimento de Material Educativo Digital. Renote - Revista Novas Tecnologias na Educação, maio 2005.

Hylén, J. (2007). What are digital learning resources? Recuperado de http://itforpedagooger.skolverket.se/in_english/digital_learning_resources/what/

Lévy, P. (2000). Cibercultura. Carlos Irineu da Costa. São Paulo: Editora 34.

Mourato, D. (2011). As Tecnologias Solidárias: do Investimento ao desenvolvimento pessoal. Tese de Doutoramento em Educação. Universidade de Lisboa, Instituto de Educação.

OCDE, Centre for Educational Research and Innovation, (2007). Giving Knowledge for Free - The Emergence of Open Educational Resources, OECD Publishing: Pembroke, MA.

Pinto, M. (2007). Evaluación de la cálida de recursos electrónicos educativos para el aprendizage significativo. Sacausef 2, 25-43. http://www.crie.min- edu.pt/files/@crie/1225103966_03_CADERNOII_p25_43_MPpdf.pdf

Ponte, J. P. (2002). As TIC no início da escolaridade: Perspectivas para a formação inicial de professores. Article http://repositorio.ul.pt/bitstream/10451/4202/1/02-Ponte\%20(TIC-INAFOP).pdf

Ramos, J. L. (coord.), Teodoro, V. D., Fernandes, J. P. S., Ferreira, M. F., \& Chagas, I. (2010). Portal das Escolas: Recursos Educativos Digitais para Portugal. Estudo Estratégico. Lisboa: GEPE. http://www.gepe.minedu.pt/np4/364.html

Ramos, J. L., Teodoro, V. D., \& Ferreira, M. F. (2011). Recursos Educativos Digitais: Que Futuro?. DGIDC.

Ramos, J.L., Duarte,V.D., Carvalho, J.M., Ferreira, F.M. e Maio,V.M. (2007). Modelos e práticas de avaliação de recursos educativos digitais. Cadernos SACAUSEF nº. II, pp.79-87.

República, D. da. (2008). Decreto-lei nº3 /2008, de 7 de janeiro. Lisboa, Portugal: Governo de Portugal.

Ribeiro, L. (2002). O boom da nova economia ou o esvaziar da bolha?. Em M. Carrilho (orgs.), Novos Média, Novas Políticas? - Debater a Sociedade da Informação,14-24. Oeiras: Celta.

Scremin, A., Schumacher, J. (2019). Ser Aluno e Paciente: Um Novo Olhar Sobre o Acesso Pedagógico Hospitalar. RELACult - Revista Latino-Americana de Estudos em Cultura e Sociedade.

Silva, J., (nd). Refletindo sobre as dificuldades da aprendizagem na Matemática. Algumas considerações. Recuperado de https://www.ucb.br/sites/100/103/TCC/22005/JoseAugustoFlorentinodaSilva.pdf

Sparrowhawk, A., Heald, (2007). How to use ICT to support children with Special Education Needs. Cambridge: LDA

Tchounikine, P. (2011). Computer Science and Educational Software Design. A Resource for Multidisciplinary Work in Technology Enhanced Learning. Springer

UNESCO. (2009). Guide to Measuring Information and Communication Technologies (ICT) in Education. Montreal, Canada: UNESCO Institute for Statistics.

Vieira, M. A. (2005). Educação e sociedade da informação: uma perspectiva crítica sobre as TIC num contexto escolar. Doutoramento em Educação pela Universidade do Minho. Instituto de Educação e Psicologia. 